\title{
Analisis Peningkatan Kinerja Dosen melalui Implementasi Corporate Social Responsibility Internal di Universitas Muhammadiyah Ponorogo
}

\author{
Adi Santoso \\ Universitas Muhammadiyah Ponorogo \\ Korespondensi penulis: adisantoso@umpo.ac.id
}

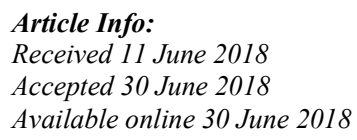
The population in this research is the entire existing lecturer in University of Muhammadiyah Ponorogo totalling 187 people using proportional stratified further allocated by random sampling techniques. The taking of the sample uses the Slovin's formula with a defined precision of 5\% found the total number of respondents as a sample research as much a withdrawal of samples of research done using proportional stratified random sampling found the number of research sample as much as 120 respondents. The results of this study found that internal CSR dimension i.e. diversity and employee support a positive and significant effect against lecturers' performance improvements in the scope of the University of Muhammadiyah Ponorogo. So it can be inferred that the work environment at the University of Muhammadiyah Ponorogo relating to diversity, there is no element of intimidation with regard to issues of gender, race, tribe, and religion so that it is managed to encourage lecturers to improve its performance. Similarly, the disclosure of the internal dimension of CSR employee support felt very motivating lecturers to enhance the quality of work and professionalism of lecturers, although one of the indicator of employee support i.e. administering payroll subject matter has not too fulfilling for lecturers.

Keywords: Diversity, Employee Support, Internal CSR, The performance of lecturers.

\section{PENDAHULUAN}

Implementasi program CSR (Corporate Social Responsibility) yang bersifat internal memberikan dampak cukup berarti terhadap kepuasan kerja sumber daya manusia (SDM) pada suatu perusahaan. Sankat dan Clemen (dalam Ardianto, 2011) menyatakan bahwa CSR diartikan sebagai komitmen dunia usaha untuk bertindak secara etis, beroperasi secara legal, dan berkontribusi untuk peningkatan kualitas hidup 
sumber daya manusia dan keluarganya, komunitas lokal, dan masyarakat secara luas. Pelaksanaan CSR perusahaan tidak hanya membawa dampak logis terhadap baik tidaknya citra perusahaan di masyarakat melainkan juga berperan dalam peningkatan kinerja dan sumber daya perusahaan yang semakin baik dari sebelumnya. Implementasi CSR tersebut dapat diwujudkan dalam peran sosial perusahaan terhadap lingkungan internal perusahaan (Forstater, 2002).

Perusahaan memiliki empat tanggung jawab utama, yaitu terhadap sumber daya manusia, konsumen, masyarakat, dan lingkungan (Anatan, 2009). Keempat hal tersebut bisa menjadi dasar pertimbangan bagi perusahaan untuk menetapkan program inti dalam melaksanakan CSR secara spesifik. Terdapat dua dimensi CSR internal pada perusahaan, yakni diversity dan employee support. Diversity merupakan keragaman kondisi dan latar belakang SDM, seperti latar belakang gender dan perbedaan suku, ras, dan agama antarSDM, sedangkan dimensi employee support merupakan wujud dari dukungan yang diberikan perusahaan kepada SDMnya sebagai bentuk pemberian motivasi kepada SDM, sehingga kinerja SDM meningkat.

Kebijakan tanggung jawab sosial dan lingkungan untuk internal telah dilaksanakan oleh Universitas Muhammadiyah Ponorogo, Jawa Timur. Beberapa bidang terkait dengan pelaksanaan tanggung jawab sosial dan lingkungan meliputi pendidikan, kebudayaan, kesehatan, dan sosial. Kegiatan yang dilaksanakan sesuai dengan programprogram tersebut dilaksanakan secara berkelanjutan. Universitas Muhammadiyah Ponorogo memiliki komitmen tinggi untuk meningkatkan kesejahteraan dan kenyamanan bekerja bagi para dosennya. Dalam mendukung komitmen tersebut, pihak manajeman merumuskan kebijakan yang bertujuan untuk mendukung sikap profesionalisme para dosennya serta kepastian pengembangan karir, pengembangan pendidikan, dan pemberian reward kepada dosen, seperti pemberian fasilitas umroh/haji gratis untuk dosen. Peningkatan kompetensi dan profesionalisme dilakukan melalui berbagai pelatihan. Program itu dilakukan dengan harapan CSR internal tersebut dapat menjadi motivasi bagi dosen untuk selalu meningkatkan kinerja dan profesionalismenya, sehingga dapat berdampak positif bagi peningkatan kinerja Universitas Muhammadiyah Ponorogo.

Secara spesifik, pengaplikasian CSR internal Universitas Muhammadiyah Ponorogo kepada para dosennya adalah pemberian beasiswa pendidikan untuk dosen agar dapat melanjutkan studinya ke jenjang pendidikan S2 dan S3 dengan batas minimal sebanyak enam orang dosen setiap program studi untuk melanjutkan studi lanjut S3 setiap tahunnya. Selain pemberian beasiswa lanjut studi, Universitas Muhammadiyah Ponorogo juga melaksanakan pendidikan dan pelatihan (diklat) profesi. Saat ini, 50\% dosen di lingkup Universitas Muhammadiyah Ponorogo telah memiliki sertifikat profesi yang salah satu manfaatnya sangat penting bagi dosen, yakni untuk melakukan pengurusan jabatan fungsional ke depannya. Untuk CSR internal di segi penggajian untuk dosen, Universitas Muhammadiyah Ponorogo telah melakukan perbaikan tunjangan kinerja dan tunjangan khusus terkait prestasi akademik maupun nonakademik. Universitas Muhammadiyah Ponorogo juga melaksanakan diklat pimpinan (diklatpim) bagi dosen di lingkup Universitas Muhammadiyah Ponorogo yang memiliki jabatan struktural. Pihak Universitas Muhammadiyah Ponorogo juga memfasilitasi para dosen dalam kepengurusan sertifikasi dosen (serdos), kepengurusan Nomor Induk Dosen Nasional (NIDN), serta kepengurusan jabatan fungsional bagi dosen di lingkup Universitas Muhammadiyah Ponorogo. 
Pengaplikasian CSR internal yang dilakukan Universitas Muhammadiyah Ponorogo terhadap para dosen memiliki tujuan khusus, yakni untuk meningkatkan kinerja dosen. Kinerja dosen yang baik akan dapat berdampak positif bagi dosen dan universitas. Dosen dapat dikatakan memiliki kinerja yang baik adalah dosen yang: (1) berprestasi sebagai dosen, (2) mengembangkan diri sebagai staf akademik, (3) mengikuti perkembangan ilmu pengetahuan dan teknologi, (4) menyusun program kerja, (5) mengoptimalkan sumber daya program studi, (6) mengelola administrasi Tri Dharma Perguruan Tinggi, (7) melaksanakan tugas Tri Dharma Perguruan Tinggi, (8) melaksanakan tugas penunjang lainnya, (9) berkepribadian kuat, (10) memiliki visi dan memahami misi program studi, (11) mengambil keputusan, dan (12) menemukan gagasan baru (Natapriatna, 2001). Dengan pengaplikasian CSR internal kepada dosen di lingkup Universitas Muhammadiyah Ponorogo diharapkan kinerja dosen di lingkup Universitas Muhammadiyah Ponorogo terus meningkat positif.

\section{MODEL PENELITIAN}

Pelaksanaan dimensi CSR internal, yakni diversity dan employee support yang baik dan benar akan memperbaiki aktivitas universitas. Perbaikan tersebut ditandai dengan munculnya keunggulan kompetitif di internal universitas yang akan berdampak dalam peningkatan kualitas dan profesionalisme dosen. Menurut Kavei (2007), seorang pakar manajemen dari Universitas Manchester, menyatakan bahwa CSR dapat dipraktikkan di tempat kerja, implementasinya mencakup aspek: kesehatan dan keselamatan kerja, pengembangan knowledge dan skill karyawan, dan peningkatan kesejahteraan. Kerangka penelitian ini secara skematis ditunjukkan pada Gambar 1 yang dibentuk atas dasar teori dan konsep yang telah dikemukakan pada bagian sebelumnya.

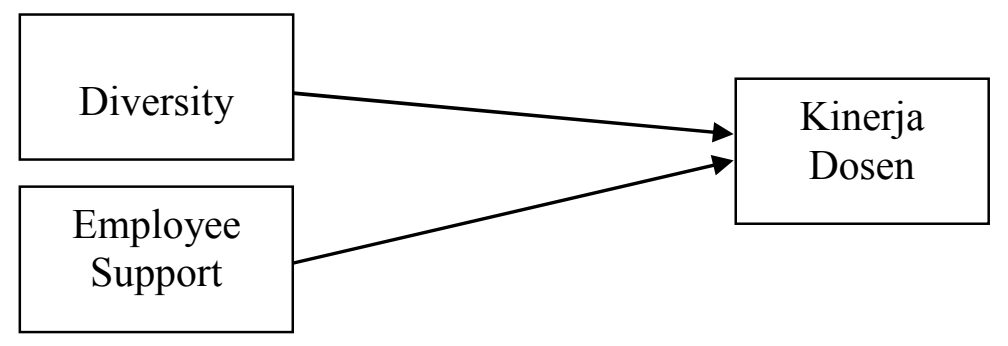

\section{Gambar 1. Kerangka Penelitian}

\section{HIPOTESIS PENELITIAN}

Hipotesis dalam penelitian ini dirumuskan sebagai berikut:

H1: Diduga diversity berpengaruh signifikan terhadap peningkatan kinerja dosen di lingkup Universitas Muhammadiyah Ponorogo.

H2: Diduga employee support berpengaruh signifikan terhadap peningkatan kinerja dosen di lingkup Universitas Muhammadiyah Ponorogo.

\section{METODE PENELITIAN}

Populasi dalam penelitian ini adalah seluruh dosen yang bekerja di lingkup Universitas Muhammadiyah Ponorogo, yakni 164 orang dosen. Penentuan responden dalam penelitian ini dilakukan dengan menggunakan proportional stratified random 
sampling sebanyak 120 responden dengan teknik pengambilan sampel menggunakan rumus Slovin dengan presisi yang ditetapkan sebesar 5\%.

\section{ANALISIS REGRESI}

Untuk mengetahui ada tidaknya pengaruh variabel bebas, yakni diversity dan employee support terhadap variabel terikat, yakni peningkatan kinerja dosen, maka dilakukan analisis regresi linear berganda dengan menggunakan bantuan program SPSS versi 20. Berdasarkan hasil pengolahan data, maka diketahui hasil untuk analisis regresi linear berganda untuk kinerja dosen adalah:

Tabel 1. Hasil Perhitungan Regresi berganda Kinerja Dosen

\begin{tabular}{lrrr}
\hline \multicolumn{1}{c}{ Variabel } & $\begin{array}{c}\text { Koefisien } \\
\text { Regresi }\end{array}$ & t-hitung & \multicolumn{1}{c}{ Signifikan } \\
\hline Konstanta & 4,306 & 4.046 & 0,000 \\
\hline Diversity (X1) & 0,416 & 3.212 & 0,002 \\
\hline Employee Support (X2) & 0,436 & 3,010 & 0,003 \\
\hline $\boldsymbol{R}$ Square & $\mathbf{0 , 4 3 8}$ & & \\
\hline F-hitung & $\mathbf{4 5 , 5 8 5}$ & & $\mathbf{0 , 0 0 0}$ \\
\hline
\end{tabular}

Sumber: Data primer diolah, 2016.

Dari Tabel 1 di atas, sebuah persamaan regresi linier berganda dapat dirumuskan sebagai berikut:

$$
Y=4,306+0,416 \times 1+0,436 \times 2
$$

Dari persamaan regresi linear berganda tersebut, nilai konstanta (a) menunjukkan angka sebesar 4,306, yang artinya bahwa jika jumlah CSR internal (diversity dan employee support) sebesar nol (0), maka kinerja dosen akan meningkat sebesar 4,306\%. Dari nilai konstanta terlihat bahwa ada keterikatan antara CSR internal terhadap kinerja dosen di lingkup Universitas Muhammadiyah Ponorogo. Hal ini menunjukkan adanya kesesuaian antara hasil penelitian dengan teori CSR yang mengungkapkan bahwa pelaksanaan CSR internal yang baik dan benar akan memperbaiki aktivitas perusahaan. Yang dimaksud perusahaan dalam konteks ini adalah Universitas Muhammadiyah Ponorogo. Untuk melihat pengaruh masing-masing variabel dari dimensi CSR internal, yakni diversity dan employee support terhadap peningkatan kinerja dosen dapat dijelaskan dengan menggunakan uji t (Tabel 2).

\section{Tabel 2. Uji Parsial}

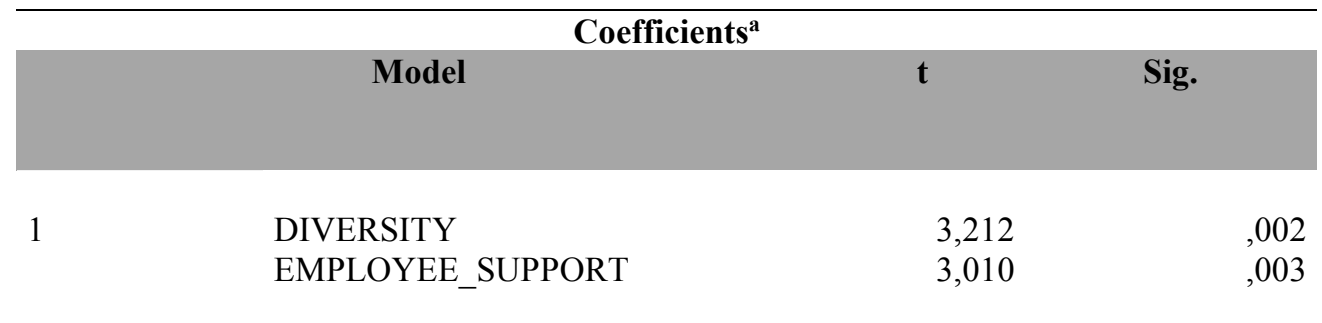

Sumber: Data primer diolah, 2016. 
Berdasarkan uji t (Tabel 2) di atas dapat disimpulkan bahwa sacara parsial variabel diversity dan employee support memiliki hubungan positif dan berpengaruh signifikan terhadap variabel kinerja dosen di lingkup Universitas Muhammadiyah Ponorogo. Hal ini dapat dilihat pada tingkat signifikansi variabel diversity dan employee support sebesar 0,002 dan 0,003 lebih kecil dari tingkat signifikansi 0,05 yang telah ditetapkan. Selain membandingkan tingkat signifikansi untuk melakukan uji hipotesis dapat menggunakan cara membandingkan nilai $t$ hitung dengan nilai $t$ tabel. Sebuah variabel dapat dikategorikan memberikan pengaruh yang signifikan, jika nilai t hitung lebih besar dibandingkan nilai t tabel. Dari hasil pengolahan data tersebut ditemukan bahwa nilai t hitung variabel diversity sebesar 3,212 dan variabel employee support sebesar 3,010, sedangkan $\mathrm{t}$ tabelnya sebesar 1,657. Hasil ini menunjukkan bahwa nilai $\mathrm{t}$ hitung variabel diversity dan employee support lebih besar dibandingkan nilai t tabel, sehingga kesimpulan yang dapat ditarik adalah variabel diversity dan employee support memiliki hubungan positif dan berpengaruh signifikan terhadap peningkatan kinerja dosen.

Hasil uji t ini menunjukkan bahwa hipotesis pertama (H1), yakni dugaan adanya pengaruh antara diversity terhadap peningkatan kinerja dosen terbukti dan hipotesis kedua (H2), yakni dugaan adanya pengaruh employee support terhadap peningkatan kinerja dosen juga terbukti. Jadi, variabel dimensi CSR internal, yakni diversity dan employee support cukup berpengaruh terhadap peningkatan kinerja dosen di lingkup Universitas Muhammadiyah Ponorogo yang dapat dilihat pada nilai t hitung, yakni masing-masing 3,212 dan 3,010.

\section{PEMBAHASAN}

Hasil penelitian ini menunjukkan bahwa dimensi CSR internal, yakni diversity dan employee support berpengaruh signifikan terhadap kinerja dosen di lingkup Universitas Muhammadiyah Ponorogo, sehingga CSR internal yang selama ini diterapkan dan diungkapkan oleh Universitas Muhammadiyah Ponorogo kepada seluruh tenaga pengajarnya mampu berdampak positif terhadap peningkatan kinerja mereka. Pengungkapan CSR ini berhasil menjadi pendorong atau memotivasi dosen untuk meningkatkan produktifitas dan profesionalisme dosen, sehingga hal ini diharapkan juga memberikan dampak positif terhadap peningkatan kinerja universitas dalam jangka panjang.

Pengungkapan CSR internal berpengaruh positif terhadap peningkatan kinerja dosen, sehingga hal tersebut harus menjadi perhatian serius bagi pihak Universitas Muhammadiyah Ponorogo untuk selalu melakukan perbaikan dalam pengungkapan CSR internal. Pelaksanaan CSR internal pada dimensi diversity dan employee support yang baik akan berdampak pada perbaikan aktifitas Universitas Muhammadiyah Ponorogo. Faktor pendorong perbaikan pengungkapan CSR internal yang dapat digunakan oleh Universitas Muhammadiyah adalah timbulnya keunggulan kompetitif dan profesionalisme dosen, sehingga keunggulan kompetitif dosen ini perlu didukung dengan perbaikan dalam pengungkapan CSR internal agar nantinya berdampak positif terhadap peningkatan kualitas dan aktifitas Universitas Muhammadiyah Ponorogo.

Universitas Muhammadiyah Ponorogo menganggap penting pengungkapan CSR internal sebagai bentuk upaya membangun rasa peduli, persahabatan, dan rasa saling memiliki antara dosen dan Universitas Muhammadiyah Ponorogo yang diwujudkan dalam berbagai aktifitas sosial sesuai dengan yang telah diatur oleh Undang-Undang 
nomor 40 tahun 2007 tentang tanggung jawab sosial dan lingkungan. Pengungkapan CSR pada dimensi diversity sangat baik di lingkup Universitas Muhammadiyah Ponorogo. Hal ini tercermin pada jumlah dosen perempuan yang berjumlah $51 \%$ dari 187 orang jumlah dosen yang ada di Universitas Muhammadiyah Ponorogo. Bahkan 48\% dari jumlah jabatan struktural yang ada di lingkup Universitas Muhammadiyah Ponorogo dijabat oleh dosen perempuan. Hal ini menunjukkan bahwa tidak ada intimidasi gender dalam perekrutan dosen dan pemilihan jabatan struktural di lingkup Universitas Muhammadiyah Ponorogo.

Hasil penelitian ini menemukan pengaruh signifikan diversity terhadap kinerja dosen yang tidak mendukung hasil penelitian Chang (2010) yang menemukan bahwa di wilayah Asia, konsep keragaman atau diversity masih menjadi kendala dan sumber persaingan di Jepang dan Korea. Hal tersebut disebabkan oleh karakter kedua negara yang sangat homogen dengan latar belakang kesukuan dan dominasi laki-laki yang lebih tinggi dibandingkan perempuan, sehingga mereka menemukan bahwa diversity tidak berpengaruh signifikan terhadap komitmen karyawan.

Telah terwujudnya workforce diversity di lingkup Universitas Muhammadiyah Ponorogo, seperti semakin beragamnya angkatan kerja dosen dari segi gender, ras, suku, dan usia. Hal ini dapat dilihat dari latar belakang dosen di Universitas Muhammadiyah Ponorogo yang tidak hanya berasal dari putra daerah atau lokal, tetapi juga ada yang berasal dari luar daerah bahkan luar pulau, yakni berasal dari Jawa Barat, Kalimantan, dan Sulawesi. Diversity yang diterapkan dengan baik dan positif dapat memberikan dorongan bagi dosen untuk meningkatkan kreatifitas dan profesionalisme dosen dan mampu memberikan sudut pandangan yang berbeda-beda mengenai berbagai masalah yang timbul dalam lingkungan kerja. Namun, jika konflik yang timbul tidak ditangani dengan baik, maka dapat menjadi permasalahan baru, seperti permasalahan komunikasi antardosen dan konflik antarpersonal yang lebih banyak lagi.

Faktor-faktor yang dapat mendorong motivasi sebesar $60 \%$ berhubungan dengan pemenuhan kebutuhan sosio-psikologi, seperti umpan balik, rasa memiliki, keterbukaan, kejujuran, kredibilitas, kepercayaan, keadilan, perhatian, tanggung jawab, dan partisipasi. Kemudian, sekitar $20 \%$ berhubungan dengan pemenuhan kebutuhan intelektual, seperti rasa pemenuhan diri, tugas yang menarik dan bervariasi, dan tantangan. Selanjutnya, $10 \%$ berhubungan dengan kebutuhan yang menunjang rangsangan materi, dan hanya $10 \%$ yang menganggap kualitas ruangan untuk bekerja sebagai dorongan yang penting (Nawawi, 1997).

Dengan ditemukannya pengaruh positif diversity dan employee supprot selaku dimensi CSR internal terhadap peningkatan kinerja dosen di lingkup Universitas Muhamamdiyah Ponorogo menunjukkan bahwa CSR internal yang diungkapkan atau direalisasikan oleh Universitas Muhammadiyah Ponorogo dapat menumbuhkan semangat dan memotivasi para dosen dalam meningkatkan kinerjanya, sehingga hal itu dapat mengurangi frekuensi pergantian atau turnover dosen. Para dosen dapat bekerja dengan disiplin dan profesional, karena mereka memiliki pandangan positif bahwa pihak Universitas Muhammadiyah Ponorogo akan selalu memperhatikan hak mereka. Semangat dan motivasi serta pandangan positif terhadap Universitas Muhammadiyah Ponorogo akan mendorong dosen untuk berkarya dan berprestasi, sehingga berdampak terhadap kinerja dosen dan berdampak positif pula pada kinerja Universitas Muhammadiyah Ponorogo. 
Beberapa program CSR internal di lingkup Universitas Muhammadiyah Ponorogo menggunakan pendekatan religius, seperti program umroh dan haji bagi dosen tetap di lingkup Universitas Muhammadiyah Ponorogo. Program umroh dan haji ini diberikan kepada dosen tetap dengan indikator masa kerja dan prestasi yang telah ditorehkan olehnya, sehingga dosen tetap dengan masa kerja yang belum lama, tetapi memiliki prestasi kerja yang baik berhak pula untuk mendapatkan program haji dan umroh dari lembaga. Hal ini menjadi salah satu motivasi bagi dosen tidak tetap untuk memperbaiki kinerja mereka, sehingga bisa segera diangkat menjadi dosen tetap dan menikmati program CSR internal yang berkaitan dengan program umroh dan haji tersebut.

Pelaksanaan tanggung jawab sosial internal ini tidak hanya memberikan konsekuensi logis terhadap baik tidaknya citra Universitas Muhammadiyah Ponorogo di mata para dosen selaku sumber daya manusianya. Pelaksanaan CSR internal universitas juga berperan dalam meningkatkan kinerja sumber daya manusia yang dimilikinya. Implimentasi CSR internal dapat diwujudkan dengan peran sosial Universitas Muhammadiyah Ponorogo di lingkungan internal universitas, dalam hal ini berkaitan dengan kesejahteraan hidup para dosennya (Forstater, 2002).

Dalam jangka panjang, pengungkapan CSR internal ini akan menciptakan kinerja dosen yang lebih baik dan membawa dampak terhadap peningkatan kualitas individu dosen dalam aktifitas belajar dan mengajar bagi mahasiswa, sehingga mampu berkontribusi terciptanya mahasiswa yang berkualitas. Upaya tersebut akan memudahkan lulusan untuk mendapatkan pekerjaan yang diinginkan dan berkarya serta berprestasi di lingkungan masyarakat. Dengan kemampuan Universitas Muhammadiyah Ponorogo dalam menciptakan mahasiswa berkualitas, maka akan memberikan dampak pada peningkatan citra universitas, sehingga menjadi nilai tambah bagi daya tarik calon mahasiswa baru untuk melanjutkan studinya di Universitas Muhammadiyah Ponorogo. Sebagai universitas swasta, salah satu indikator yang mendorong Universitas Muhammadiyah Ponorogo untuk dapat berkembang adalah jumlah mahasiswa baru yang meningkat di setiap tahunnya.

\section{KESIMPULAN DAN SARAN}

\section{Kesimpulan}

Kesimpulan yang dapat ditarik dari hasil penelitian ini menunjukkan bukti empiris tentang pengaruh dimensi CSR internal, yakni diversity dan employee support terhadap peningkatan kinerja dosen Universitas Muhammadiyah Ponorogo, yaitu:

1. CSR internal dengan dimensi diversity (X1) dan employee support (X2) berpengaruh positif dan signifikan terhadap peningkatan kinerja dosen di lingkup Universitas Muhammadiyah Ponorogo.

2. Universitas Muhammadiyah Ponorogo telah cukup baik dalam merealisasikan CSR internal. Selama ini, program CSR internalnya cukup memberikan dampak positif dalam mendorong kinerja dosen.

\section{Saran}

Berdasarkan kesimpulan dari hasil penelitian yang diuraikan sebelumnya, maka ada beberapa saran yang diajukan sebagai bahan pertimbangan dan masukan sebagai upaya untuk membangun dan meningkatkan kinerja dosen di Universitas Muhammadiyah Ponorogo, yaitu: 
1. Pihak Universitas Muhammadiyah Ponorogo perlu melakukan peningkatan atau perbaikan konsep employee support bagi dosen, misalnya konsep insentif yang lebih baik.

2. Pihak Universitas Muhammadiyah Ponorogo perlu melakukan peningkatan pada konsep diversity, karena masih ditemukan beberapa masalah antarpersonal dalam lingkungan kerja yang berdampak pada suasana lingkungan kerja yang rentan menimbulkan konflik antardosen.

\section{DAFTAR REFERENSI}

Anatan, L. (2009). Corporate Social Responsibility (CSR): Tinjauan Teoritis dan Praktik di Indonesia, Vol 8 No 2.

Ardianto, E. D. (2011). Efek Kedermawanan Pebisnis dan CSR. Jakarta: PT. Elex Media Komputindo.

Chang, E. M. (2010). Diversity management and the effect on employees organizational commitment: Evidence from Japan and Korea. Jurnal of World Bussiness.

Forstater, P. R. (2002). Corporate Social Responsibility: Implications for Small and Medium Enterprises in Developing Countries. Vienna: United Nations Industrial Development Organization (Unindo).

Kavei, G. (2007). Corporate Social Responsibility and Human Research Development: A Perspective from Hamibian Private Business. University of Manchester.

Natapriatna, S. (2001). Kinerja Kepala sekolah: Studi Korelasi antara Pengetahuan tentang Manajemen Sekolah dan Sikap terhadap Jabatan dengan Kinerja Kepala SD di Kotamadya Depok. IKIP Jakarta.

Nawawi, H. (1997). Manajemen Sumber Daya Manusia untuk Bisnis yang Kompetitif. Yogyakarta: Gadjah Mada University Press. 